\title{
Acoplamentos, Vínculos e Deficiência Visual: sobre um vetor de atravessamento Varela-Latour
}

\author{
Couplings, articulation and visual disability: \\ About a transverse vector Varela-Latour
}

\begin{abstract}
Resumo: O artigo analisa um dos vetores de atravessamento das obras de Francisco Varela e Bruno Latour, enfocando o entendimento singular acerca do que habitualmente é concebido como relação no âmbito da ciência moderna. Aponta que tanto Varela nas ciências da cognição, quanto Latour nos estudos sobre ciência deslocam a noção de relação, entendida como ligação entre pólos pré-existentes, em favor de noções como rede, acoplamento estrutural e vínculo, que possibilitam pensar processos imanentes de invenção do mundo, envolvendo humanos e não-humanos. O texto procura ainda demonstrar que, em função de tais deslocamentos conceituais, as obras de Varela e Latour constituem referências teóricas importantes para os estudos sobre deficiência visual.

Palavras-chave: Rede. Acoplamento Estrutural. Vínculo. Deficiência Visual.
\end{abstract}

Abstract: This article analyzes one of the transversal vectors of Francisco Varela and Bruno Latour's work, focusing on the singular understanding about what is commonly known as relation in the scope of modern science. It shows that both Varela, in cognition sciences, and Latour, in the studies about science, shift the concept of relation, understood as the connection between pre-existing poles, favoring notions such as network, structural coupling and articulation, which enable us to think immanent processes of world invention, involving humans and non-humans. The text also seeks to demonstrate that, because of those conceptual shifts, Varela and Latour's works are important theoretical references for the studies on visual disability.

Keywords: Network. Structural Coupling. Articulation. Visual Disability.
KASTRUP, Virgínia; TSALLIS, Alexandra. Acoplamentos, Vínculos e Deficiência Visual: sobre um vetor de atravessamento Varela-Latour. Informática na Educação: teoria \& prática, Porto Alegre, v. 12, n. 2, p. 12-22, jul./dez. 2009.

\author{
Virgínia Kastrup \\ Universidade Federal do Rio de Janeiro \\ Alexandra Tsallis \\ Universidade Federal do Rio de Janeiro
}

\section{I ntrodução}

rancisco Varela e Bruno Latour foram amigos muito próximos e, segundo Amy Cohen, eram almas gêmeas ${ }^{1}$. A amizade foi desenvolvida durante o período em que Varela morou na França e trabalhou no Centre de Recherche en Épistémologie Appliquée (CREA). Amigos que se freqüentavam e que regularmente trocavam idéias sobre seus trabalhos, o diálogo Varela-Latour não chegou a assumir lugar de destaque em suas respectivas obras, embora citações recíprocas tenham ocorrido com alguma freqüência.

$\mathrm{Na}$ obra de Varela, é recorrente a presença do conceito de Latour de quase-objeto. Este comparece na crítica dirigida às dicotomias sujeito-objeto, natureza-artifício e indivíduosociedade, tanto na discussão sobre práticas de produção de subjetividade (COHEN;

1 Expressão usada durante a jornada de estudos A la croisée de la philosophie phénoménologique, de la neuro-biologie et des traditions spirituelles - En hommage à Francisco Varela, realizado por ocasião de sua morte, na Maison Heinrich Heine, na Cité Universitaire, Paris, em outubro de 2001. Amy Cohen, esposa de Varela, esteve com Latour na mesa onde este fez a conferência de encerramento da jornada. 
VARELA, 2000) quanto nas discussões de ordem epistemológica (DEPRAZ; VARELA; VERMERSCH, 2003). Na década de 90, sua proposta de desenvolvimento de uma ciência da experiência por métodos complementares de terceira e primeira pessoa (VARELA; SHEAR, 1999) encontra em Latour - aqui referido como um dos representantes da recente história e filosofia das ciências - um importante aliado. Na ocasião, Varela busca conferir respeitabilidade científica ao estudo da experiência por métodos de primeira pessoa e defende que sua qualidade subjetiva deve ser claramente distinguida de algo privado ou inacessível. A experiência pode ser explicitada, analisada e submetida à validação intersubjetiva por meio de métodos precisos de descrição que permitem seu estudo científico. Argumenta que divisões como fora-dentro ou objetivo-subjetivo são enganadoras e aponta que as descrições em terceira pessoa, supostamente objetivas, possuem também uma dimensão subjetiva-social, embora esta seja escondida pelas práticas científicas, elas mesmas sociais. Reunidas sob a rubrica de método científico, há uma série de regulamentações procedurais que envolvem referências mentais e também sociais, o que aponta que as investigações ditas objetivas não podem ser caracterizadas como lidando com coisas meramente externas.

Por sua vez, Latour (TEI L; LATOUR, 1995) cita Varela no texto The Hume Machine: can associations networks do more than formal rules?, destacando a similaridade entre seu trabalho e aquele desenvolvido por Varela, Thompson e Rosch no livro L'inscription corporelle de l'esprit (traduzido para o português como Mente Incorporada em 2003), no que se refere à idéia de rede. Ele considera que sua argumentação por uma teoria de rede ${ }^{2}$ se aproxima da abordagem conexionista no âmbito das ciências da cognição, por não ceder aos reducionismos, apostando na riqueza de investigar os fenômenos em sua emergência.

A estação de trabalho [Hume Machine] é a contribuição para o debate que vem tomando forma entre as ciências da cognição e a nova sociologia da ciência. Ao invés da estéril oposição entre psicologia e sociologia, nós propomos que se escolha no interior [from within] de

2 Vale mencionar o termo em inglês, network theory, para destacar a palavra trabalho, work, ali presente. Quando propõe essa teoria a idéia de trabalho é inseparável daquela de rede, ou seja, a rede é resultante de trabalho e não uma instância transcendente na qual se inscrevem os acontecimentos (TSALLIS; FERREIRA; MORAES; ARENDT, 2006) cada campo as escolas de pensamento que dêem origem a associações férteis. (TEIL; LATOUR, 1995, p. 11 , tradução nossa)

Já em 2002, no artigo How to talk about the body? The normative dimension for science studies, tece uma discussão a respeito do corpo, enquanto uma aprendizagem de ser afetado. Para tal fim, explicita o debate filosófico entre qualidades primárias e secundárias, bem como combate o dualismo que dispõe sujeitos e objetos em pólos antagônicos. É nesse âmbito que remete ao livro de Varela e Shear (1999) sobre metodologias de primeira pessoa, conforme a argumentação que apresentamos acima. Enfim, o que mais reúne Varela e Latour em tais textos é a tradução do problema epistemológico no problema da produção da ciência por práticas concretas.

Muitos são os trabalhos que realizam intercessões consistentes entre os dois autores, potencializando o diálogo Varela-Latour. Os trabalhos exploram temas diversos como a análise das condições de uma psicologia da invenção de si e do mundo (KASTRUP, 2007), a articulação entre cognição e emoção (ROCHA, 2007), o corpo em conexão na prática do Sistema Rio Aberto de Pozzana de Barros (BARROS, 2008), a dimensão enativa da atenção a si nos métodos de primeira pessoa (VASCONCELOS, 2009) e o problema da autonomia no interior de uma proposição de psicologia não-moderna (ARENDT, 1999), dentre outros.

O objetivo deste texto não é fazer um levantamento minucioso e exaustivo de suas citações recíprocas, e sim examinar um dos vetores de atravessamento da obra de ambos, que é o entendimento bastante singular do que é entendido por relação no âmbito da ciência moderna. Pretendemos demonstrar que tanto Varela nas ciências da cognição, quanto Latour nos estudos sobre ciência deslocam a noção de relação entendida como ligação entre pólos pré-existentes, em favor de noções como as de acoplamento estrutural, de rede e de vinculo. Estas possibilitam pensar processos de invenção da cognição - científica ou não - e do mundo. Procuraremos também demonstrar a partir de situações concretas, que em função desses deslocamentos conceituais, as obras de Varela e Latour constituem referências teóricas importantes para os estudos sobre deficiência visual. 


\section{Círculo e a Rede}

Nos estudos da cognição o conceito de relação comparece sempre que, adotando o modelo da representação, nos referimos ao conhecimento como uma relação sujeito-objeto. Segundo tal modelo, o conhecimento coloca em relação um sujeito cognoscente e um objeto que se dá a conhecer. Sujeito e objeto são aí considerados pólos pré-existentes e mesmo fundamentos do processo de conhecer. $\mathrm{Na}$ abordagem realista é o objeto que assume a condição de fundamento, enquanto na abordagem idealista é o sujeito é que se encontra em tal posição. Realismo e idealismo não se opõem, mas são duas faces da mesma moeda (KASTRUP; TEDESCO; PASSOS, 2008). O conceito de relação sustenta também os modelos interacionistas que, evitando os fundamentalismos objetivo e subjetivo, defendem uma reciprocidade e uma influência mútua entre os pólos da relação, sejam eles sujeito e objeto, organismo e ambiente ou indivíduo e sociedade. Além de ligar sujeito e objeto, o conceito de relação também é utilizado para ligar outras realidades supostamente separadas como organismo e ambiente, indivíduo e sociedade, mente e corpo. O entendimento da realidade através de dicotomias é uma marca da modernidade e constitui uma característica marcante da psicologia cognitiva, bem como de abordagens em ciências da cognição reunidas sob a rubrica de cognitivismo computacional (KASTRUP, 2007). Segundo Latour (1991), esta maneira de pensar resulta de práticas de purificação de uma realidade sempre híbrida.

Desde o período em que Francisco Varela trabalhou com Humberto Maturana formulando a teoria da autopoiese, a chamada relação sujeito-objeto foi deslocada e mesmo subvertida. Sujeito e objeto são doravante entendidos como efeitos do processo de conhecer. As práticas concretas produzem, num movimento de co-engendramento, sujeitos cognoscentes e objetos conhecidos. A ação ou prática ocupa o lugar do meio, um meio que, em lugar de unir realidades préexistentes, responde pela criação concreta das extremidades. Não se trata apenas de considerar que o organismo é modificado pelo ambiente, mas também o modifica. Não é apenas reconhecer que o social constitui o indivíduo, mas o indivíduo também constitui o social. Ou ainda que o corpo determina a mente e também vice-versa. Não basta o pensamento e a linguagem do interacionismo. Ao começarem pelo meio, ou seja, pela ação, e proporem um mecanismo do coengendramento, introduzem uma perspectiva inventiva que o conceito de autopoiese busca evidenciar. O que é importante ressaltar é que o primado do meio, ou seja, das práticas, introduz um novo plano ontológico, essencial ao entendimento dos processos inventivos, que os fundamentalismos e os interacionismos não chegaram a considerar.

No contexto da biologia do conhecimento surge a noção de acoplamento estrutural (MATURANA; VARELA, 1995, p. 113). Neste momento, este é definido ainda como interações recorrentes e estáveis entre o organismo e o ambiente. Apesar do vocabulário empregado, a noção traz como novidade a consideração de tais interações como perturbações recíprocas, cujo resultado são mudanças estruturais mútuas. Maturana e Varela propõem pensar organismo e meio com base nos processos que Ihes dão forma. Organismo e meio são resultados, efeitos de uma rede processual, constituindose reciprocamente e apresentando-se como fontes mútuas de perturbação. O meio não preexiste como um espaço ou continente onde o organismo vai ter sua existência, mas é constituído pelo organismo como um ambiente de vida. Por outro lado, a estrutura do organismo resulta da história de seus acoplamentos estruturais com meios específicos. Seres vivos e ambiente se definem como séries marcadas por dinâmicas distintas, ambos em deriva. Tais devires podem ser ditos aparalelos, coderivas, pois se cruzam e se afetam mutuamente. São relativamente independentes, embora causem efeitos recíprocos. Acoplamentos asseguram a sobrevivência do organismo, mas não são determinados pela pressão de um meio absoluto nem pelo programa genético, possuindo uma ampla margem de improvisação e aproveitamento de circunstâncias.

O mecanismo de constituição do sistema vivo é denominado clausura operacional. A noção de clausura operacional busca dar conta da operação de formação de uma unidade estabilizada, coerente e distinta espacialmente do que constituirá, a partir de então, o seu meio. Enquanto unidade viva possui uma natureza autopoiética, permanecendo imersa na rede processual da qual emergiu. Neste sentido, é uma estrutura definida espacialmente, mas 
que se conserva em devir. Varela e Maturana referem-se a ela como um sistema fechado, com o intuito de distingui-lo do sistema de entradas e saídas, característico da teoria da informação. Mas para Varela é claro: "clausura não é fechamento “ (VARELA, 1989, p. 217). A noção de clausura busca evidenciar que o resultado de uma operação situa-se dentro das fronteiras do sistema e não que o sistema não tenha relações com o fora.

Na década de 90 Varela formula a abordagem da enação, com a qual pretende desenvolver a crítica do mentalismo, levando mais longe o problema da corporificação do conhecimento. A segunda idéia a ser desenvolvida é a dimensão de invenção de mundo que as práticas cognitivas comportam, enfatizando ainda mais seu afastamento do modelo da representação (VARELA; THOMPSON; ROSCH, 2003). Em relação ao primeiro ponto, Varela refere-se à separação mente-corpo como a angústia cartesiana. Para a abordagem da enação, mente e corpo não são duas substâncias diferentes e separadas, mas algo que foi separado por práticas concretas. Seguindo Latour (1991), são práticas de purificação, que atravessam e caracterizam a modernidade. Antes de perguntar como mente e corpo entram em relação, devemos argüir acerca das práticas que produzem tal separação. Discernindo quais são tais práticas, podemos então resgatar um domínio híbrido, onde a mente se corporifica e/ou o corpo se espiritualiza. É possível também, por este caminho, reduzir a angústia do processo de conhecer.

Desmontar a separação e, portanto, a relação mente-corpo, é também desmontar a relação sujeito-objeto. Corporificar o conhecimento é criar acoplamentos diretos, sem a mediação da representação. Como já apontamos, o caso da aprendizagem da flauta (VARELA; THOMPSON; $\mathrm{ROSCH}, 2003$ ) é exemplar. No princípio o corpo é comandado pela mente. A aprendizagem começa com regras e representações, com instruções simbólicas dadas pelo professor e seguidas pelo aprendiz. Mas aprender a tocar flauta não é seguir regras. A aprendizagem só avança quando a relação simbólica é transformada em acoplamento direto do corpo com o instrumento, eliminando o intermediário da representação. Nos termos de Varela, tratase de enação, encarnação ou corporificação do conhecimento. A cognição passa a funcionar em acoplamento direto com a matéria que o mundo fornece.

Aprender não é adequar-se à flauta, mas agenciar-se com ela. Há aí uma nítida aproximação com o conceito de agenciamento de G. Deleuze e F. Guattari (1977). Agenciamento é comunicação direta, sem mediação da representação. É comunicação sem subordinação, hierarquia ou determinismo. O agenciamento não opera por causalidade, mas por implicação recíproca entre movimentos, processos, ou fluxos heterogêneos, por dupla captura. Trata-se aqui da produção de uma unidade complexa aprendiz-instrumento, capaz de produzir um processo de diferenciação recíproca.

Se entendemos o aprender flauta como um agenciamento maquínico, aprender resta sendo eliminar distâncias. Aprende-se entre a boca e a flauta, aprende-se no meio, na superfície de seu acoplamento, fora do campo da representação. Como no caso da adaptação com o meio, trata-se de tirar partido dos constrangimentos materiais da flauta. Tira-se partido da flauta quando o movimento de soprar consegue agenciar-se com a disposição do instrumento e gerar, ao mesmo tempo, o som e o aprendiz (KASTRUP, 2008, p. 105-106).

É oportuno lembrar que a abordagem da enação surge na esteira das abordagens da emergência, compartilhando com elas a crítica ao cognitivismo computacional e ao entendimento da cognição como processamento simbólico por regras lógicas. No lugar de uma causalidade linear e unidirecional, adota-se o modelo da rede, de causalidade multiníveis. A causalidade clássica cede lugar a relações recíprocas, de codeterminação. A articulação de elementos subsimbólicos se dá como um constrangimento mútuo, onde a tensão é mantida. A emergência não é apenas uma síntese de elementos, é a produção de realidades inéditas. Pode-se dizer ainda que a rede aproxima sem totalizar, sendo possível a coexistência de díspares. No entanto, Varela se afasta dos modelos da emergência como o de J ohn Searle, na medida em que rompe radicalmente com o modelo da representação (VARELA, 1989).

Para esclarecer tal concepção de causalidade, Varela cita Latour: “processos emergentes são redes de causalidade: elas são constituídas pela disseminação de causas e efeitos que trazem manifestações que não podem ser reduzidas a nenhuma causa única" (LATOUR, 1994 apud COHEN; VARELA, 2000). Enfim pode-se dizer que o círculo é desenhado e redesenhado a partir da rede da qual emerge, tendo seus limites constantemente reconfigurados. $\mathrm{O}$ 
corpo cognitivo é um círculo, ao mesmo tempo que uma rede.

\section{A Rede e o Vínculo}

Bruno Latour parte do interesse pelas práticas científicas em ação para sustentar a idéia de jamais termos sido modernos. O autor propõe a noção de não-moderidade, para enfatizar a impossibilidade de separar instâncias como sujeito e objeto. "A distinção de objetos e sujeitos não é primitiva, ela não designa domínios diferentes de mundo: ela somente remete a uma fratura da ação" (LATOUR, 2000, p. 198). Essa proposta vislumbra habitar o mundo e pensá-lo sem sair dele, isto é, não instalar mecanismos de retirada que evitem os acontecimentos. Não fabricar explicações que tentem separar o que, no mundo, está misturado.

No entanto, remeter à mistura do mundo não significa uma recusa das diferenças, pelo contrário, busca acompanhá-las na fabricação sempre singular de suas trajetórias. Para isso, a proposta é trabalhar denominando a todos como actantes ${ }^{3}$. O termo actante tem sua origem na semiótica e busca designar, simplesmente, aquele que age. Dessa forma, pode ser utilizado de maneira simétrica tanto para humanos quanto para não-humanos. Em poucas palavras, Latour (2001, p. 346) afirma que "o segredo é definir o ator com base naquilo que ele faz".

É fundamental entender que os actantes acontecem no mundo e não é possível saber de antemão quais serão aqueles que estarão agindo em uma determinada situação. Eles poderão ser assim determinados somente quando agirem de fato e/ou quando deixarem seu traço. "Se eles agem, eles deixam algum traço, então você pode ter alguma informação, então você pode falar sobre eles. Caso contrário, cala-se [ ... ]." (LATOUR, 2002a, p. 7, tradução nossa) Para tal fim, é crucial perceber as nuances de cada actante na rede, isto é, estar atento aos vínculos e às traduções que se operam através destes. A noção de vínculo permite acompanhar os actantes em ação, isto é, sem paralisá-

3 Ainda que no decorrer de sua obra Bruno Latour também utilize a designação ator, optamos por trabalhar com a noção de actante, uma vez que ele a propõe como alternativa para escapar à identificação com a idéia de ator social, exclusiva para humanos. los ou mesmo reificá-los. Já traduzir significa deslocar informações na rede, contemplando sua possibilidade de produzir desvios e gerar por sua vez múltiplas apropriações.

Em síntese, os vínculos e as traduções são como a rede se coloca em ação. Dessa forma, é possível pensar na relação não como a conexão entre instâncias separadas, mas como um movimento que se distribui pelos diversos actantes. Nesse sentido, o mundo não pode ser concebido a partir de um patamar superior (transcendente) que dê inteligibilidade ao patamar inferior (imanente). Em outras palavras, sua proposta abre mão das grandes narrativas para acompanhar a trajetória dos acontecimentos buscando uma cenarização, qual seja, os acontecimentos serão descritos para que se forme um panorama do que está sendo acompanhado. A cenarização tem como característica a provisoriedade, ou seja, remete constantemente à retomada dos actantes em ação (LATOUR, 2004).

Em relação a isso, Iñiguez (2003) esclarece que essa proposta não trabalha com um mundo que é construído do mesmo modo que se constrói um edifício, isto é, não se pode imaginar uma construção que, uma vez terminada, fica pronta e pode ser simplesmente ocupada. A construção é um processo ininterrupto de práticas que mantém o mundo de tal ou qual maneira. É justamente por essas práticas que Latour vai se interessar em suas pesquisas.

Sem dúvida, isso exige que o ponto de partida seja no baixo mundo e não se afaste um momento sequer da complexa associação de humanos e não-humanos, denominada coletivo (LATOUR, 2001). A expressão baixo mundo tem um sentido positivo e se refere justamente à recusa de recorrer a níveis de entendimento metafísicos, o que resulta em uma opção pela imanência ao invés da transcendência (LATOUR, 2002b). Tendo em vista essa proposição, é possível encarnar, isto é, pensar no corpo não como algo distinto da mente, mas como um território sensível, bem como em ação.

Para apresentar essa concepção podemos tomar o título do texto Como falar sobre o corpo? (LATOUR, 1999). Latour parte da idéia do corpo enquanto possibilidade de afetação, o que resulta na impossibilidade de distinção entre qualidades primárias (referentes ao mundo / objetos) e qualidades secundárias (referentes ao homem / sujeitos). Portanto, o corpo não é pensado como uma entidade, 
uma instância, e sim espaço de invenção de acontecimentos. Concepção essa muito próxima daquela proposta por Varela.

Ter um corpo é aprender a ser afetado, significando 'efetuado', movido, colocado em movimento por outras entidades, humanas ou não-humanas. Se você não está engajado neste aprendizado você se torna insensível, idiota, você cai morto. (LATOUR, 1999, p. 1, tradução nossa)

Para pensar o corpo dessa forma descreve o treinamento dado na indústria de perfumes para ensinar às pessoas a aprimorarem seu olfato. O objetivo é que, ao final, elas se tornem um nariz - expressão francesa para designar aqueles treinados na arte da distinção de fragrâncias. Esse processo se dá pela sucessiva exposição dos aprendizes à maleta de odores que, por sua vez, está organizada em uma sequência específica de essências puras em uma gradação de contrastes.

Inicialmente, essa associação heterogênea de humano (pessoa, nariz) e não-humano (maleta, fragrâncias) consegue distinguir apenas de maneira grosseira os odores. É com o desenrolar dos encontros entre a maleta e o nariz que vai se delineando um acontecimento que resulta na redefinição de ambos. O nariz passa a ter capacidade de identificar nuances que pareciam não afetá-lo e, na mesma direção, a maleta revela gradações que se configuram a partir de novos elementos olfativos. Vale ressaltar que a palavra corpo perde sua associação unívoca com os humanos, sendo simetricamente distribuída também pelos nãohumanos. Assim, já não é possível discriminar - lugar de origem de um nariz, bem como explicar as nuances da experiência, utilizando categorias prévias tais como sujeito e objeto.

Citamos Latour,

Ele não moveu simplesmente os aprendizes (alunos) da desatenção à atenção, da semi-consciência à avaliação consciente, mas os ensinou a serem afetados, efetuados pela influência das substâncias químicas que, antes da sessão, bombardearam suas narinas em vão - efeito e afeto se originam de facere e são casos daquilo que denominei fe(i)tiche (LATOUR, 1999, p. 2).

O termo fe(i)tiche ${ }^{4}$ se refere à impossibilidade de separar aquilo que é feito (fetiche), daquilo que é um fato. O conceito de fetiche é uma espécie de resposta à acusação

4 Em francês o termo utilizado é faitiche, que guarda a similaridade gráfica com a palavra francesa fetiche, substituindo o início pelo termo fait, que significa fato e, ao mesmo tempo, feito. de que determinado objeto não passa de um somatório de projeções e crenças de um sujeito (LATOUR, 2002b). Em outra direção, os fe(i)tiches são ações que não exigem que se escolha entre um fato ou uma crença, pelo contrário assumem a mistura entre o real e o fabricado apostando nos vínculos como ponto de partida. Em síntese, mais do que a mera invenção de uma palavra, busca-se performar, nessa concepção, o mundo pensado a partir dele próprio e não a partir de dicotomias préexistentes.

\section{A Perda da Visão e a Reinvenção da Rede}

Seguindo nossa argumentação, o conhecimento do mundo não se dá por meio de relações entre sujeitos e objetos préexistentes. Conhecer é inventar um mundo, inventando a si mesmo, de modo recíproco e indissociável. Com tal formulação, tanto Varela quanto Latour fornecem subsídios para abordar o estudo da deficiência visual sob outra perspectiva: ela deixa de ser um problema individual que se projeta num meio social, bem como não pode ser explicada pela lógica da produção social de um evento. O não-ver não é uma forma natural nem uma maneira artificial de estar no mundo, não se esgota nem no indivíduo nem na sociedade, não cede à distinção mente e corpo. Em poucas palavras, exige que sejam colocados em cena os diversos actantes capazes de produzir como efeito isso que denominamos deficiência visual.

A investigação evidencia que se trata de um fenômeno complexo, que não comporta qualquer tipo de reducionismo. Precisa ser abordado como um efeito emergente de uma rede de vínculos fisiológicos, materiais, discursivos, tecnológicos, políticos, etc. Uma pessoa que perde a visão perde, num mesmo movimento, uma rede de vínculos que constitui seu mundo. Ficar cego não é apenas perder a função visual, mas é enfrentar a experiência de desterritorialização e o desafio de reinventar seu modo de perceber e de viver. Sendo assim, construir novos vínculos, sejam eles com coisas ou com pessoas, é um desafio diário que precisa ser colocado em ação a cada momento. 


\subsection{Primeira Cenarização}

Durante uma entrevista, um homem cego morador da cidade do Rio de Janeiro fez a seguinte colocação: Quando cheguei aqui no Benjamin Constant é que fiquei sabendo que eu era deficiente visual. Até então eu pensava que tinha um problema no nervo ótico. Qual o sentido que tal formulação comportava? A palavra deficiente não traz consigo uma condição de inferioridade e uma indesejável idéia de uma identidade cega? Não foi por esta conotação que se deu sua substituição pela expressão pessoa portadora de deficiência, mais tarde substituída por pessoa portadora de necessidades especiais? O homem falava de sua descoberta de que era deficiente visual num sentido que parecia positivo. Seria isto mesmo? Não era evidente que ter um diagnóstico de deficiente visual fosse melhor do que ter um problema no nervo ótico. Enfim, o de problema no nervo ótico era um diagnóstico oftalmológico e parecia isento de conotações pejorativas. Mas o homem considerava realmente positiva a denominação de deficiente visual. Era um homem falante, que não relatava experiências de fracasso e não revelava dúvida sobre sua capacidade de conviver bem com a sua condição de cego. Tenho a mente aguçada. Às vezes penso que não vou conseguir fazer alguma coisa, mas quando vejo eu já fiz. Minha mente vai na minha frente. Além disso, era casado, parecia ter o apoio afetuoso da mulher e da família e participava com empenho das aulas de cerâmica e de outras oficinas.

Com a análise cuidadosa da entrevista, foi possível concluir que a expressão deficiente visual não era o mais importante e não funcionava para ele como um rótulo identitário. Como deficiente visual, teve acesso no Instituto Benjamin Constant a uma nova rede de pessoas e atividades, inclusive a da oficina de cerâmica, que abriu a possibilidade para receber uma série de cuidados e informações, inclusive sobre dispositivos técnicos - relógios que falam as horas e binóculos especiais, dentre outros - que o ajudam hoje a levar sua vida. Enfim, ser deficiente ampliou sua rede de vínculos e expandiu seu território existencial. O que o homem relatava era o desprendimento de um território fechado, fruto de um problema oftalmológico progressivo e incurável, que se viu inesperadamente aberto através do acesso a uma rede heterogênea de pessoas e coisas, de utensílios e cuidados, e conseqüentemente de novas possibilidades de existência e de transposição de limites existenciais.

\subsection{Segunda Cenarização}

Certo dia, durante uma entrevista, ouvimos uma história curiosa de um homem que havia perdido gradativamente a visão e estava quase totalmente cego. Ela evidencia bem o quanto a abertura de novos vínculos com o mundo pode significar uma reinvenção existencial para algumas pessoas que se tornam deficientes visuais. O homem narrou que naquela manhã havia saído para fazer um exame de sangue e levou um livro em braile para ler enquanto esperava ser atendido. Estou na fila, 6 horas da manhã. Ai o pessoal ficou cochichando. Aqueles cochichos, bate-papozinhos, né? 'Ele é cego', 'este rapaz é cego', 'é leitura de cego', achando uma coisa de outro mundo. Aí eu comecei a fazer um ar de riso, não estou nem ai. Porque eu tô só lendo o meu livrinho, porque eu tenho que ler pra sexta-feira, pra dar aula pras crianças, pro pessoal, né? Eu tenho que estar bem afiado. Eu tenho que praticar bastante nesse livro. Aí eu fico imaginando: será que é tão duro pensar que esse aqui é um livro de quem sabe ler? Porque eles deviam imaginar isso, né? Ao invés de 'ah, este é um livro de cego!', deviam pensar: esse é um livro de quem sabe ler. [ . . . ] Se pegar um livro escrito em japonês, que é só uns garranchos assim, uns pontos, pouca gente sabe ler. Mas não é um livro de quem sabe ler?

O homem se pergunta por que tanto espanto em ver uma pessoa na fila lendo um livro que, afinal, é uma cena normal na vida cotidiana. Aos poucos fomos entendendo que se tratava de um homem que havia trabalhado como cozinheiro ao longo de toda sua vida. Imigrante nordestino, não havia tido oportunidade de freqüentar a escola em sua cidade natal, nem no Rio de Janeiro, onde trabalhava duro num restaurante. Quando seu problema visual se agravou, ele foi aposentado. Freqüentando o Instituto Benjamin Constant, teve oportunidade, aos quase cinqüenta anos de idade, de ser alfabetizado em braile. Hoje ensina numa oficina de braile para crianças e adultos. Ele afirma: Quando nós vamos perdendo a visão, no meu caso, eu cheguei aqui desesperado porque eu pensei que tinha se acabado o mundo. Mas mentira, porque 
nasceu um outro mundo. Eu sou muito mais feliz hoje do que quando eu enxergava normal [ . . . ] O estudo me fez perceber que não é só da visão que nós vive. Então, o assunto é esse. Eu aprendi muito depois que comecei a vir aqui.

E continua: Todo tipo de doença devia ter uma casa igual ao Instituto [ . . . ] Porque no Instituto não se trata da visão, se trata da mente. Quantas pessoas chegam aqui cegas? Quantas pessoas chegam aqui com vista e sai cego, e sai sorrindo? E sai feliz? Pode fazer uma pesquisa aí. Porque chega enxergando e sai daqui cego, e sorrindo, feliz. É diferente. Abre outros horizontes, outras vidas, outros meios de viver, outras maneiras de viver. Isso não tem dúvida. Volta e meia eu escuto 'Sai de lá cego'. Mas tu saiu com outra visão, com palestras, com outra vida, vivendo independente. É isso que você tem feito. Ninguém sai 'ah, porque eu tô cego'. Pouca gente, pouca gente. Não tem como. Enfim ele comenta acerca do preconceito dos videntes para com as pessoas cegas: Acontece que eles não sabem da capacidade de fazer as coisas que eu tenho, sem eles. Às vezes eu brinco com um colega. Eu fico triste quando a pessoa diz que enxerga e não coloca linha numa agulha. Eu boto. Mas é porque eu aprendi. Eu vim pra escola pra aprender. Eu vim pra escola pra aprender, por exemplo, a fazer costura, a pregar botão... Na minha camisa, se soltar algum botão, eu coloco.

\subsection{Terceira Cenarização}

Durante atendimentos clínicos realizados em grupo pudemos escutar em vários momentos que um dos elementos que identifica um cego é a bengala. Ela não é meramente um objeto. Na maior parte das vezes, é feita de alumínio na forma tubular, é composta de pequenas partes articuladas, com uma ponta destinada à mão, em plástico, enquanto a outra encontra o chão, com um pequeno acabamento de borracha ou uma rodinha. Esses tubos se encaixam e desencaixam fazendo com que ela possa ficar comprida e reta ou pequena e dobrável. Quando ela toca o chão faz um som característico tic...tic, tic...tic, tic...tic. Esse tic possui um ritmo, uma cadência inconfundível aos ouvidos. Ele se escuta de um lado e depois do outro, a bengala bate e varre o espaço lendo as nuances do chão. Ela anuncia os obstáculos do percurso, estende o braço, amplia o horizonte tátil. Esses tubos de alumínio têm a capacidade de cruzar o tato com a audição situando o cego no mundo. Quando dizemos situando o cego no mundo, nos referimos às várias nuances que a expressão pode contemplar: ela o situa no espaço físico, ela o situa frente aos videntes como um cego, como um deficiente ou como alguém que merece ajuda. Além das possibilidades anteriores, ela situa aquele que não vê frente à própria cegueira.

Uma senhora nos conta: Eu posso até não enxergar, mas na hora que pegar a bengala vou ser cega. Ela afirma que tinha uma acompanhante que Ihe servia muito melhor do que uma bengala, pois com ela tinha o benefício da dúvida. Ela podia ser vista como alguém que, simplesmente, está sendo ajudada e não, necessariamente, como alguém cega. Como discutimos anteriormente, não ver não é sinônimo de ser cego - ser cego pode ser mais e melhor, assim como pode ser mais e pior. Isso depende do que os vínculos produzem em cada cenarização. Quando nos disse isso, essa mesma pessoa já tinha participado das aulas de Orientação e Mobilidade, que objetivam, entre outras coisas, ensinar o uso da bengala. Portanto, a utilidade daqueles tubos de alumínio articulados não era motivo de interesse, pelo contrário, era melhor ter uma pessoa-bengala ao lado do que ter a certeza da cegueira.

Essa frase vinculava mais elementos. Nordestina de origem, quando era criança em sua cidade, ao final da feira, sobrava o feijão de cego, uma mistura composta por diferentes grãos. Esse nome é porque cego não pode ver que tá tudo misturado ali, coitado, come sobra. E tem mais - a mulher feia é rapariga de cego. E sobre a bengala conclui: Eu sei usar mas, não sei, não consigo. Era perceptível a emoção envolvida naquele relato. Os outros participantes Ihe contavam sobre as vantagens da bengala: Você vai poder andar sozinha, ir à igreja, não vai mais precisar ficar trancada. Ainda assim, isso não valia o preço de ser cega, ainda mais ser cega com essas memórias que, por sua vez, multiplicam as referências pejorativas. Ela escutava o grupo e respondia: Um dia ... um dia vou tentar.

$\mathrm{Na}$ sequência daquela conversa outra pessoa toma a palavra. Agora era um rapaz cego fazia um pedido à equipe terapêutica: Podemos fazer um passeio um dia. Eu fico muito sozinho, quero sair, a gente pode sair 
daqui e fazer nosso encontro perto da natureza, é bom pra gente. Conversamos e combinamos, iríamos caminhar até a Praia Vermelha na semana seguinte. Frente a isso, quem sabe, nós psicólogos, podíamos pedir que o benefício da dúvida que até o momento favorecia o vínculo com a acompanhante também pudesse favorecer a bengala e, quem sabe, vinculála com mais elementos. Entre risos, o acordo foi feito: iríamos caminhar juntos, a senhora, o feijão de cego, a bengala, a rapariga de cego, a cegueira, a rua e a psicóloga. Naquela experiência, os vínculos já presentes - bengala, feijão de cego, rapariga de cego, cegueira se viram frente a novas possibilidades. Agora também estavam presentes naquele cenário os sons da rua, o sol quente, o oferecimento de ajuda por parte de transeuntes, a sensação de vento, o cheiro de mar, entre outros. Aquele acontecimento- passeio estava povoado de sensações. Portanto, a potência da bengala não estava sendo somente destacada pela fala dos colegas, mas estava sendo, mais do que tudo, sentida no corpo. Foi assim que esse passeio se tornou um marco, pois reinventou a bengala assim como aquela senhora. A partir desse dia ela pode ser vista recusando a ajuda da acompanhante e pedindo que a deixasse chegar ao grupo apenas com a bengala. Já a bengala, por outro lado, não articulava somente um conjunto de tubos à certeza da cegueira, mas também produzia a possibilidade de muitas outras sensações.

\section{Conclusão}

As noções de acoplamento, bem como de vínculo - para além das ressonâncias que foram trabalhadas no decorrer do texto - possuem um elemento em comum, que é sua articulação com a idéia de rede. Rede que se agencia no baixo mundo, rede que se estabelece pelo feixe dos acontecimentos em ação. Portanto, não se trata de evocar a rede como uma imagem estática, mas destacá-la em seu caráter volátil, apropriado quando se deseja trabalhar com a dinâmica das práticas. Como decorrência disso, a própria concepção de ação, de prática, pode ser pensada fora do antagonismo entre determinação e liberdade. A rede não determina o actante, nem tampouco o actante, para ser livre, precisa sair da rede. Pelo contrário, quanto mais vinculado, mais livre, pois são os vínculos que permitem os deslocamentos na rede: quanto maior o número vínculos, maior a possibilidade daquele actante mobilizar novas proposições e produzir novos cenários.

Dessa forma, é a partir do meio que as perguntas devem ser feitas. O meio não é sinônimo de relação. No interior das perspectivas propostas por Varela e Latoour tal conceito se vê exigido a um deslocamento radical: as instâncias sujeito - objeto não serão mais pré-existentes, e sim pós-existentes. O que significa que precisam ser encaradas como efeitos, ao invés de pontos de partida. Retomar aos vínculos e acoplamentos em seu processo de transformação impede que continuemos a operar com as fórmulas de relação sujeitoobjeto ou sujeito-sujeito.

No caso específico da deficiência visual, os problemas habitualmente colocados podem ser recolocados. Neste caso, a pergunta o que é a deficiência visual perde o sentido. Temos que entender como, na falta da visão, aquela vida se articula. Já não basta perguntar a que devemos recorrer para explicar a cegueira: se aos problemas do nervo ótico, se às dificuldades de inserção social, se ao braile ou à bengala. É preciso investigar quais são os vínculos em ação e que efeitos eles geram em determinado cenário. A partir dessa indagação, o caráter provisório das cenarizações também poderá funcionar como um fértil território de reinvenção tanto de humanos quanto de nãohumanos. Em outras palavras, tomar como ponto de partida a experiência da cegueira no baixo mundo significa não situá-la nem no indivíduo, nem na sociedade, nem no corpo, nem na mente, mas trabalhá-la enquanto uma zona de dispersão, que exige um esforço, por parte de todos, em renunciar às dicotomias e começar a pensar na cegueira a partir de seus acoplamentos e vínculos.

Tal formulação possui uma evidente ressonância política, uma vez que não é possível pensar a deficiência visual para além dos vínculos por meio dos quais ela é fabricada. Ela é engendrada na imanência das ações. A ressonância política extrapola a dimensão macropolítica, ensejando também o desenvolvimento de micropolíticas com o intuito não apenas de refletir sobre a fabricação da deficiência mas, sobretudo, para propor novos vínculos e acoplamentos que podem ser produzidos, no sentido de aumentar o grau de liberdade e circulação destes actantes na rede. 


\section{Referências}

ARENDT, R.J.J. Para Onde Vai a Psicologia?: por uma abordagem contemporânea da autonomia. 1999. Tese (Doutorado) - Universidade Estadual do Rio de Janeiro, 1999, Rio de Janeiro, BR-RJ.

BARROS, L. P. O Corpo em Conexão: Sistema Rio Aberto. Niterói: EDUFF, 2008.

COHEN, A.; VARELA, F. Facing Up to the Embarrassment: The practice of subjectivity in neuroscientific and psychoanalytic experience. Journal of European Psychoanalysis: humanities, philosophy, psycotherapies, $\mathrm{n}$. 10/11, winter-fall 2000. Disponível em: <http://www.psychomedia.it/jep/number10-11/cohe-varela.htm> Consultado em julho de 2009.

DELEUZE, G.; GUATTARI, F. Kafka: por uma literatura menor. Rio de Janeiro: I mago, 1977.

DEPRAZ N.; VARELA, F.; VERMERSCH, P. On becoming aware. Amsterdam: John Benjamins Publishing, 2003.

IÑIGUEZ, L. La psicologia social en la encrucijada postconstrucionista: historicidad, subjetividad, performatividad, accion. [S.I.: s.n.], 2003. Conferência de abertura do XII Encontro Nacional da ABRAPSO, realizado na PUCRS, 2003, Porto Alegre, BR-RS.

LATOUR, B. Jamais Fomos Modernos. Rio de Janeiro: Ed.34, 1991.

LATOUR, B. Latour, Postmodern! No, simply, Amodern! Steps towards an Anthropology of science. Science studies in History and Philosophy, London, v. 21, n. 1, p. 145-171, 1993.

LATOUR, B. How to talk about the body?: The normative dimension of science studies. 1999. Disponível em: <http://www. bruno-latour.fr/> Acesso em: maio 2004.

LATOUR, B. Factures/fractures: de la notion de réseaux à celle d'attachement. In: MICOUD, A. ; PERONI, M. Ce qui nous relie. La Tour d'Aigues: Ed. de l'Aube, 2000. P. 189-208.

LATOUR, B. A Esperança de Pandora. Bauru: EDUSC, 2001.

LATOUR, B. A Dialog on Ant. 2002a. Disponível em: <http://www.ensmp.fr/ latour/articles/article/090.html> Acesso em: set. 2003.

LATOUR, B. Reflexão Sobre o Culto Moderno dos Deuses Fe(i)tiches. Bauru: EDUSC, 2002 b.

LATOUR, B. Políticas da Natureza: como fazer ciência na democracia. Bauru: EDUSC, 2002a.

KASTRUP, V. A Invenção de Si e do Mundo: uma introdução do tempo e do coletivo no estudo da cognição. Belo Horizonte: Autêntica, 2007.

KASTRUP, V. A Cognição Contemporânea e a Aprendizagem Inventiva. In: KASTRUP, V.; TEDESCO, S.; PASSOS, E. Políticas da Cognição. Porto Alegre: Sulina, 2008. P. 93-112.

MATURANA, H.; VARELA, F. A Árvore do Conhecimento. Lisboa: Editorial Psy, 1995.

ROCHA, J. M. Os Múltiplos Nós que Nos Constituem: o afeto na constituição dos processos emotivos e cognitivos. Orientação: Virgínia Kastrup. 2007. Tese (Doutorado) - Programa de Pós-Graduação em Psicologia, Universidade Federal do Rio de Janeiro, 2007, Rio de Janeiro, BR-RJ .

TEIL, G.; LATOUR, B. The hume machine: can association network do more than formal rules?. SEHR, Stanford, v. 4, n. 2, p. 80-93, 1995. 
TSALLIS, A.C.; FERREIRA, A.A.L.; MORAES, M.O.; ARENDT, R.J.J . O que Nós Psicólogos Podemos Aprender com a Teoria Ator-Rede?. Interações, Campinas, v. 11, p. 57-86, 2006.

VARELA, F. Autonomie et Connaissance. Paris: Seuil, 1989.

VARELA, F.; SHEAR, J. (Ed.). The view from within: first person approaches to the study of consciousness. Thorverton: Imprint Academic, 1999.

VARELA, F.; THOMPSON, E.; ROSCH, E. A Mente Incorporada. Porto Alegre: Artmed, 2003.

VASCONCELOS, C. S. Atenção a Si: da auto-observação à auto-produção. Orientação: Virgínia Kastrup. 2009. Tese (Doutorado) - Programa de Pós-Graduação em Psicologia, Universidade Federal do Rio de Janeiro, 2009, Rio de Janeiro, BR-RJ.

Recebido em agosto de 2009

Aprovado para publicação em setembro de 2009

\section{Virgínia Kastrup}

Professora do Programa de Pós-Graduação em Psicologia da Universidade Federal do Rio de Janeiro - email: virginia.kastrup@gmail.com

\section{Alexandra Tsallis}

Pós-doutoranda do Programa de Pós-Graduação em Psicologia da Universidade Federal do Rio de Janeiro email: atsallis@gmail.com 